\title{
A tale of two population crises in recent Chinese history
}

\author{
Harry F. Lee • David D. Zhang
}

Received: 17 December 2010 / Accepted: 25 April 2012 / Published online: 12 May 2012

C The Author(s) 2012. This article is published with open access at Springerlink.com

\begin{abstract}
The fall of the Ming dynasty in the first half of the 17th century and the Taiping Rebellion from 1851-1864 were two of the most chaotic periods in Chinese history, and each was accompanied by large-scale population collapses. The 'Kang-Qian Golden Age' (also known as 'High Qing'), during which population size expanded rapidly, falls in between the two. Scholars remain divided in their opinions concerning the above alternation of population growth and decline as to whether variations in population size or climate change should be identified as the root cause. In either case, the synergistic impact of population growth and climate change upon population growth dynamics is overlooked. In the present study, we utilized high-resolution empirical data, qualitative survey, statistical comparison and time-series analysis to investigate how the two factors worked synergistically to drive population cycles in 16001899. To facilitate our research, we posited a set of simplified pathways for population growth in historical agrarian China. Our results confirm that the interrelation between population growth, climate change and population crises in recent Chinese history basically followed our posited pathways. The recurrences of population crises were largely determined by the combination of population growth and climate change. Our results challenge classic Malthusian/post-Malthusian interpretations and historians' views of historical Chinese population cycles.
\end{abstract}

\section{Introduction}

The fall of the Ming dynasty in the first half of the 17th century and the Taiping Rebellion in 1851-1864 were two of the most chaotic periods in Chinese history. ${ }^{1}$ The consequences for China were devastating; those periods were marked by rampant natural calamities, widespread social unrest, deadly military conflicts and finally, large-scale population collapses. In 1626-1646, population size in China dropped from 99.9 million to 88.5 million (a decline of

\footnotetext{
${ }^{1}$ The term Chinese history used in this study is basically about the history of monsoon China, in which low temperature associates with weak summer monsoon (Chen et al. 2008; 2010).

H. F. Lee $(\bowtie) \cdot$ D. D. Zhang

Department of Geography and the International Center of China Development Studies, University of Hong Kong, Pokfulam Road, Hong Kong, China

e-mail: harrylee@hku.hk

D. D. Zhang

School of Geographic and Environmental Sciences, Guizhou Normal University, Guizhou 550001, China
} 
$11.4 \%$, while in $1852-1870$, the population size dropped from 439.6 million to 357.7 million (a decline of $18.6 \%$ ) (Zhao and Xie 1988). However, between the two population crises, China experienced the 'Kang-Qian Golden Age' (also known as 'High Qing'), during which the Qing dynasty reached the zenith of its social, economic and military power. That period is characterized by rapid population growth. The data suggest a broad question: what brought about the alternation of population growth and decline, the periodic occurrence of population crises, in China in recent history?

Scholars have suggested different causal explanations: the failure (personal misconduct, mismanagement) of the 'bad-last ruler' of a dynasty (Wright 1965; Zhao 1994); the coevolution between agricultural and steppe societies along their frontiers (Lattimore 1988); the growth and decline of key economic areas (Chi 1963); the struggle between private interest in land rent and state interest in land tax (Wang 1936); the fiscal distress of internal social institutions (Huang 1988; Reischauer 1965); the random outbreak of exogenous largescale warfare (Chao 1986).

Considering the overwhelmingly agrarian nature of historical Chinese societies, where more than $90 \%$ of the population was involved in agriculture, the most widely accepted explanation for Chinese population cycles is the periodic overshooting of Malthusian limits by population size, which resulted in massive shortages for the whole societies. As stated by Malthus (1798), when population increases beyond the means of subsistence, food prices increase, real wages decline and per capita consumption, especially among the poorer strata, drops. Economic distress, often accompanied by famine, plague and war, leads to lower reproduction and higher mortality rates, resulting in slower population growth (or even decline), which in turn allows the subsistence means to catch up. Constraints on reproduction are loosened and population growth resumes, leading eventually to another subsistence crisis. In line with this rubric, many studies of Chinese socio-political and population cycles conclude that when population was large relative to land carrying capacity, further population increase would lead to state instability. At that point, internecine warfare would break out that eventually caused population decline and dynastic collapse. Thus, scholars often conclude that the primary factor causing population size to oscillate is population growth (Chen 1946; Chu and Lee 1994; Turchin 2003, 2005; Usher 1989; Wu 2003; Xiao 2005; Zhou 1997).

In contrast, several scholars have noted a strikingly strong coincidence between historical Chinese climatic, dynastic and population cycles. In short, the heydays of dynasties and rapid population growth coincided with favorable climate and vice versa (Fan 2010; Ji 1989; Jiang et al. 2004; Lan and Jiang 2005; Li 1999; Liu 1994; Long 1989; Man 2009; Pan 1994; Tang and Tang 2000, 2002; Wang 1996; Zhang 1999). Their consensus suggests that human societies are not closed systems; they are affected by the physical world. Instead of population growth, climate change is more imperative in driving the population cycles in historical China.

In their different interpretations, scholars often emphasize that either population growth or climate change alone can cause population crises in historical China. Recent studies, however, suggest that climate change resulted in human catastrophes only if the population system had already pushed against its Malthusian constraints (Stenseth and Voje 2009; Turchin and Nefedov 2009). In our latest empirical study (Lee and Zhang 2010), although climate change is shown to be an important factor in driving historical Chinese population cycles, ${ }^{2}$ the climate-population relationship is, in fact, mediated by population growth. Briefly, the above literature suggests that the mechanism may not be population growth or climate change alone, but the two factors working synergistically to drive population cycles

\footnotetext{
${ }^{2}$ We found that over the past millennium, the peaks of various population checks coincided with periods of cold climate; five of six cold phases are associated with population collapses (Lee and Zhang 2010).
} 
in historical China. In the present study, we utilized high-resolution empirical data to investigate whether the two population crises associated with the fall of the Ming dynasty and the Taiping Rebellion were triggered by the synthesis of population growth and climate change. The study period has been restricted to 1600-1899, which completely encompasses the two population crises. Climate, mortality and population data for the period are abundant and accurate, which is critically important in proving any causal relationship.

\section{Theoretical framework}

To facilitate our research, we posited a set of simplified pathways for population growth in historical agrarian China (cf. Lee and Zhang 2010) as follows:

(1) The linkage between temperature change and population growth shows up through fluctuations in agricultural production (Lee et al. 2008; Lee and Zhang 2010; Lee et al. 2009). Cooling shortens the crop growing season and reduces farmland area (Galloway 1986). Both of these are detrimental to land carrying capacity in terms of agricultural production, especially in a primarily agricultural economy characterized by a low level of technology and high dependence on favorable climate conditions. ${ }^{3}$

(2) Population pressure is co-determined by land carrying capacity and population growth. In the pre-industrial era, the speed of human innovation and its diffusion were not rapid enough to accommodate a growing population. Population pressure will naturally accumulate over time, and the Chinese population probably repeatedly reached a state of demographic saturation and equilibrated at the edge of misery, i.e. starvation (Fagan 2000; Li 1998; Nefedov 2003; Wood 1998; Wrigley 1973).

(3) The shrinkage of land carrying capacity brought on by long-term cooling further intensifies population pressure (food shortage). Social buffering mechanisms (technological advancement, inter-regional trade) were ineffective in dissipating the growing population pressure in agrarian societies, resulting in more frequent mortality events, such as famine, epidemics and civil wars (Zhang et al. 2007a).

(4) Cold periods are often associated with great climatic variability, including extremes of drought and flood, which further disturb agricultural practices already handicapped by a short growing season (Galloway 1986; Gribbin 1978). The synergy of low temperatures and increased population pressure also intensifies reclamation activities on agriculturally marginal lands, which invites more frequent natural calamities such as floods or drought (Ho 1959; Jiang 1993).

\footnotetext{
${ }^{3}$ The history of rice cultivation in the middle and lower reaches of the Yangtze River may give a more complete picture concerning the effect of cooling on the settled agricultural areas. Double cropping of rice started there in the Tang dynasty (618-906) when the climate was similar to that of today. In the Sung dynasty (960-1279), due to a cooler climate, double cropping of rice cultivation was infeasible in most of the Jiangnan region. But, in the late 15 th century, the cultivation practice was further developed. The practice reached its peak in the warm mid-16th century. The period also overlapped with the 'warm phase' in the Little Ice Age (c. 1400-1900). However, in the 17th century, the coldest period in the Little Ice Age, the double cropping system collapsed (Gong et al. 1996). Coinciding with the warmer phase that started since the early 18th century double cropping rice cultivation began to dominate the region again. Nevertheless, by the beginning of the 19th century (demarcated by a cold climate), it once more proved unsustainable despite government promotion. In the Jiangsu region, double cropping rice cultivation was no longer practiced anymore. Today, double cropping rice cultivation is again functioning successfully (Gong et al. 1996). In short, the above historical shifting of rice cultivation is basically synchronous with the long-term alternation of warm and cold phases.
} 
(5) When the productive potential of the state was weakened by long-term cooling and destroyed by ensuing civil wars, this reduced its resistance to, or even encouraged, nomadic invasions. Hence, internal warfare and nomadic invasions can be difficult to separate (Long 1989).

(6) Mass migration driven by population pressure, famine, war and natural calamities facilitated the spread of epidemics or even pandemics (Zhang et al. 2007a).

(7) Mass migration, especially nomadic migration towards settled agricultural areas, promoted disputes over land and food resources between natives and migrants, resulting in violent conflicts (Fang and Liu 1992; Zhang et al. 2007b).

(8) As the various mortality factors were often interlinked, their demographic impact was magnified, and demographic collapse followed. The resultant depopulation reduced population pressure, and mortality events subsequently decreased.

(9) This sequence was followed by renewed population growth, setting in motion another population cycle (Zhang et al. 2007a).

The pathways described in the chains of events and feedback loops are represented in Fig. 1. The reciprocal interactions among the variables along the pathways generate the alternation of population growth and decline, which are embedded within the particular environmental conditions, cultural history and socio-economic context of historical agrarian China.

\section{Data}

Based on the posited pathways (Fig. 1), we analyze the periodic occurrence of population crises in China in 1600-1899 in three steps. First, we present a qualitative survey of the interrelation between climate change, population pressure and population cycles. Then, we statistically compare the frequencies of various population checks in cold and warm phases. If the checks are more frequent in a cold climate, we can postulate climate change to be an important factor in driving historical Chinese population cycles. Lastly, we verify the various pathways in Fig. 1 by time-series analysis so as to assess the synergy of population growth and climate change in driving historical Chinese population cycles. The following data were used:

Fig. 1 Simplified pathways for population growth in historical agrarian China. The arrows are: 'Change in $\mathrm{X}$ is associated with change in $\mathrm{Y}$ '. The sign indicates whether the association is positive or negative

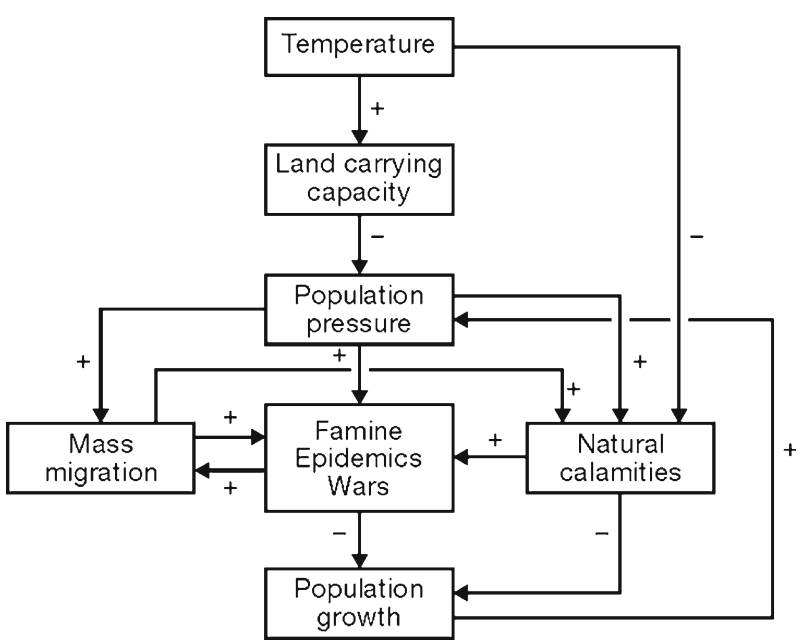


3.1 Paleo-temperature and delineation of cold \& warm phases

Yang et al.'s (2002) China-wide temperature anomaly series was chosen as the standard paleo-temperature record in this study. The series was reconstructed by combining area weighted regional multi-proxy data including ice cores, tree rings, lake sediments and historical documents (Figs. 2d \& 3a). Although there are some recent temperature reconstructions in China (Tan et al. 2003; Wang et al. 2001), their spatial coverage did not cover the entire country. Using century as the measurement unit, we took 1700-1799 to be a warm phase and 1600-1699 and 1800-1899 to be cold phases. The delineated cold and warm phases basically concur with the ones suggested by Zhang et al. (2005; 2006; 2007b).

\subsection{Population parameters}

Population size data were retrieved from Zhao and Xie's (1988) estimate of historical Chinese population size (Figs. 2a \& 3k). Their estimate is judged to be the most reliable, and it has been used by other scholars (Chu and Lee 1994; Turchin 2003, 2005, 2006; Zhang and Li 1999). Zhao and Xie (1988) give estimates of Chinese population size at irregular time intervals, and the common logarithm of the data points was taken, linearly interpolated and then anti-logged back to create an annual time series. This method avoids distortions of the population growth rate in data interpolation. Population growth rate (Figs. 2i \& 3j) was calculated by the following formula:

$$
\frac{P_{t}-P_{t-1}}{P_{t-1}} \mathrm{X} 100
$$

where $P$ is population size, and $t$ represents time step (yr).

\subsection{Agricultural production parameters}

\subsubsection{Agricultural production index}

We combined two parameters to show the fluctuation of agricultural productivity in China. The first parameter is the tree-ring growth in China, which was obtained by averaging arithmetically the tree-ring chronologies in Wulan, Huashan and Qilian Mountain. Those chronologies are publicly available from the World Data Center for Paleoclimatology (http:// www.ncdc.noaa.gov/paleo/treering.html). The second parameter was the detrended rice price for the whole of China spanned from 961 to 1910 (Peng 1965). The two parameters were normalized to homogenize the original variability of all series, and then arithmetically averaged to give the agricultural production index (Fig. 3b).

\subsubsection{Cultivated land area}

The cultivated land area data used in this study (Fig. 2b) are compiled by Ge et al. (2004). Their data spanned from 1661 to 1933. As they give estimates of cultivated land areas at irregular time intervals, the common logarithm of the data points were taken, linearly interpolated and then anti-logged back, to create an annual time-series. This method avoids any distortions of the rate of land area change in data interpolation. 


\subsubsection{Cultivated land area per capita}

It has been calculated by the total cultivated land areas (Ge et al. 2004) divided by total population size (Zhao and Xie 1988). As the cultivated land area data starts in 1661, the cultivated land area per capita also starts in the same year (Fig. 2c).

\subsubsection{Harvest indexes}

Based on the historical regional harvest reports of 66 stations in China that were kept in the Palace Museum in Beijing, Gong et al. (1996) have constructed the summer and autumn harvest indexes of grain production that spanned from 1730 to 1978. The indexes (Fig. 2e), ranging from 3.0 to 10.0 , represent the grain yield per land unit in terms of full harvest (e.g.,

Fig. 2 Relationship between climate change, population pressure and population crises in China, 1600-1899. a Population size (in 100 million, circle-dotted line) (Zhao and Xie 1988). b Cultivated land area (in 100 million hectare, square-dotted line) (Ge et al. 2004). c Cultivated land area per capita (in hectare) (cf. Section 3.3.3). d Detrended temperature index (Yang et al. 2002). e Summer (circle-dotted line) and autumn (square-dotted line) harvest indexes of grain production (Gong et al. 1996). f Total amount of grains stored in 'ever-normal granaries' (in 10 million shi) (Liang 1980). g Life losses caused by famines, epidemics, and various natural disasters (in million) (cf. Section 3.4.6). h Total number of wars (Editorial Committee of Chinese Military History 1985). i Population growth rate (\%) (Zhao and Xie 1988). The Yaxis of the panels for (g) and (h) are inverted in order that their negative association with temperature change could be visualized easily. Vertical dashed lines delineate the cold (1600-1699 \& 1800-1899) and warm (17001799) phases

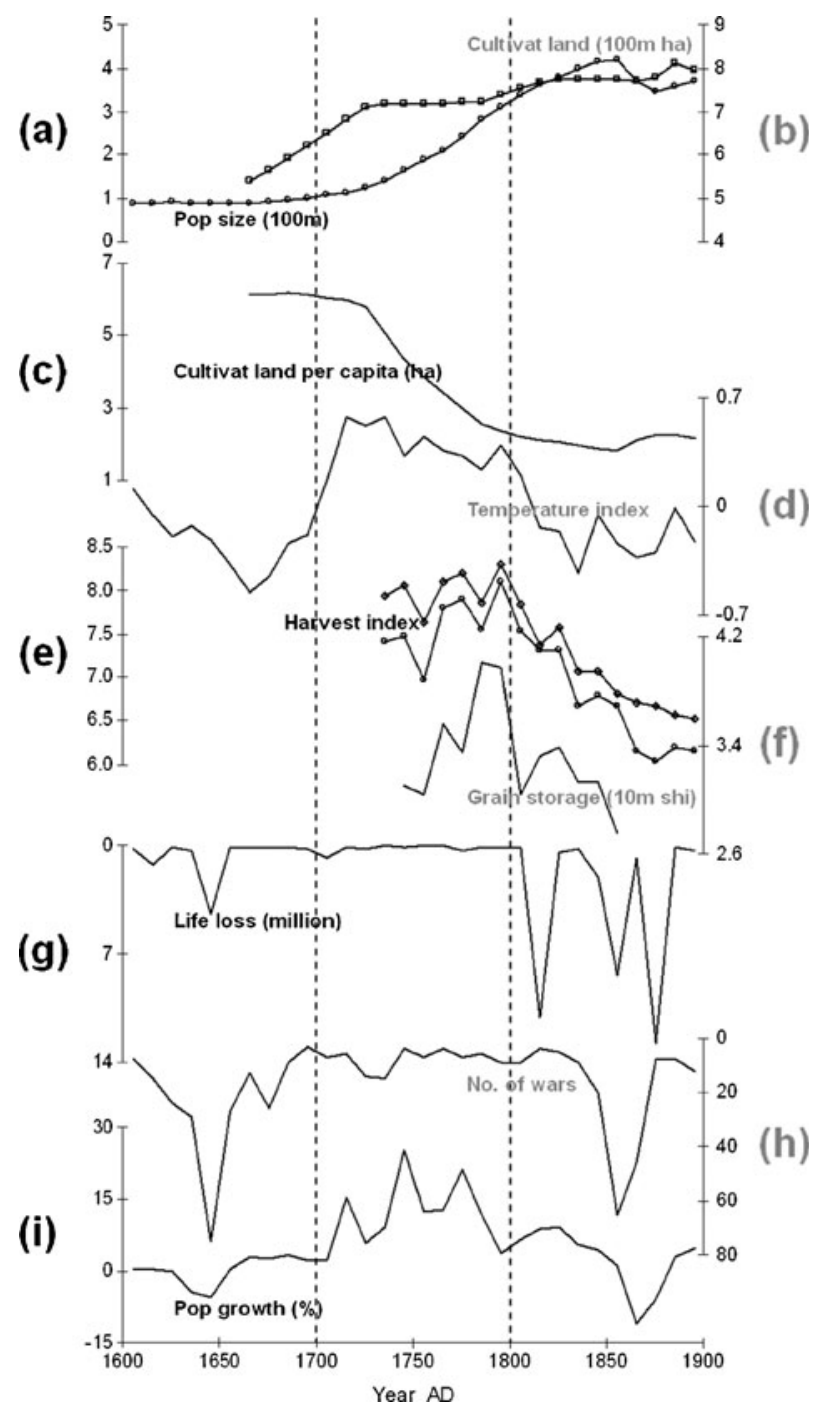


the index 5.5 indicates that grain production is only $55 \%$ of full harvest). The indexes $\geq 8.0$ and $\leq 6.0$ represent good and poor harvest, respectively.

\subsubsection{Grain storage}

This is based on the historical grain storage data collected by Liang (1980). Grain storage refers to the total amount of grains stored in the price-regulating 'ever-normal granaries' in various provinces in 1741-1850 (Fig. 2f). The grain storage record could not be kept after the Taiping Rebellion in 1851, owing to the destruction of local archives.

\subsection{Population check parameters}

\subsubsection{Famine}

Data were obtained from the chronological table compiled by the Institute of History, Chinese Academy of Social Sciences (1988) of natural hazards from 205 BCE to 1911 $\mathrm{CE}$; only those events that were classified as great famines in the original data source have been included in the chronological table. There were 94 famine years during 1600-1899 (Fig. 3c).

\subsubsection{Wars and rebellions}

A group of researchers from the Nanjing Academy of Military Sciences has compiled a multi-volume compendium which scrupulously records the wars that took place in China from $800 \mathrm{BCE}$ to $1911 \mathrm{CE}$ (Editorial Committee of Chinese Military History 1985). There were 500 wars during the period 1600-1899 (Figs. 2h \& 3d), including 267 rebellions (Fig. 3e).

\subsubsection{Epidemics}

This dataset was derived from Sun's (2004) chronological table of pestilence in China. The year of outbreak and magnitude of each epidemic are also provided in the table. There were 187 epidemics over 1600-1899 (Fig. 3f).

\subsubsection{Flood and drought disasters}

Gao (1997) documents flood and drought disasters in China from 180 BCE to 1983 CE with $>1,000$ casualties, stating the date, location and loss of life for each incident. In the present study, those data were transformed to number of provinces affected by flooding/drought disasters in a year. There were 81 flooding (Fig. 3g) and 56 drought incidents (Fig. 3h), respectively, in the period $1600-1899$.

\subsubsection{Natural calamities}

This dataset, compiled by Chen and Gao (1984), documents those climatic disasters such as typhoons, cold spells, flooding, drought, famines and epidemics with $>10,000$ casualties in the years from $180 \mathrm{BCE}$ to $1949 \mathrm{CE}$. In 1600-1899, there were 40 natural calamities (Fig. 3i). 
Fig. 3 Comparisons of temperature change, tree-ring widths, population checks and population crises of China, 1600-1899. a Detrended temperature index (Yang et al. 2002). b Agricultural production index (cf. Section 3.3.1). c Number of years with great famines (Institute of History Chinese Academy of Social Sciences 1988). d Total number of wars (Editorial Committee of Chinese Military History 1985). e Number of rebellions (Editorial Committee of Chinese Military History 1985). f Number of great epidemics (Sun 2004). g Number of flooding incidents with more than 1,000 causalities (Gao 1997). h Number of drought incidents with more than 1,000 causalities (Gao 1997). i Number of natural calamities with more than 10,000 causalities (Chen and Gao 1984). j Population growth rate (\%) (Zhao and Xie 1988). k

Detrended population size (Zhao and Xie 1988). All time series are in decadal units. The Y-axis of the panels for (c) to (i) are inverted so that their negative association with temperature change could be visualized easily. Vertical dashed lines delineate the cold (1600$1699 \& 1800-1899)$ and warm (1700-1799) phases

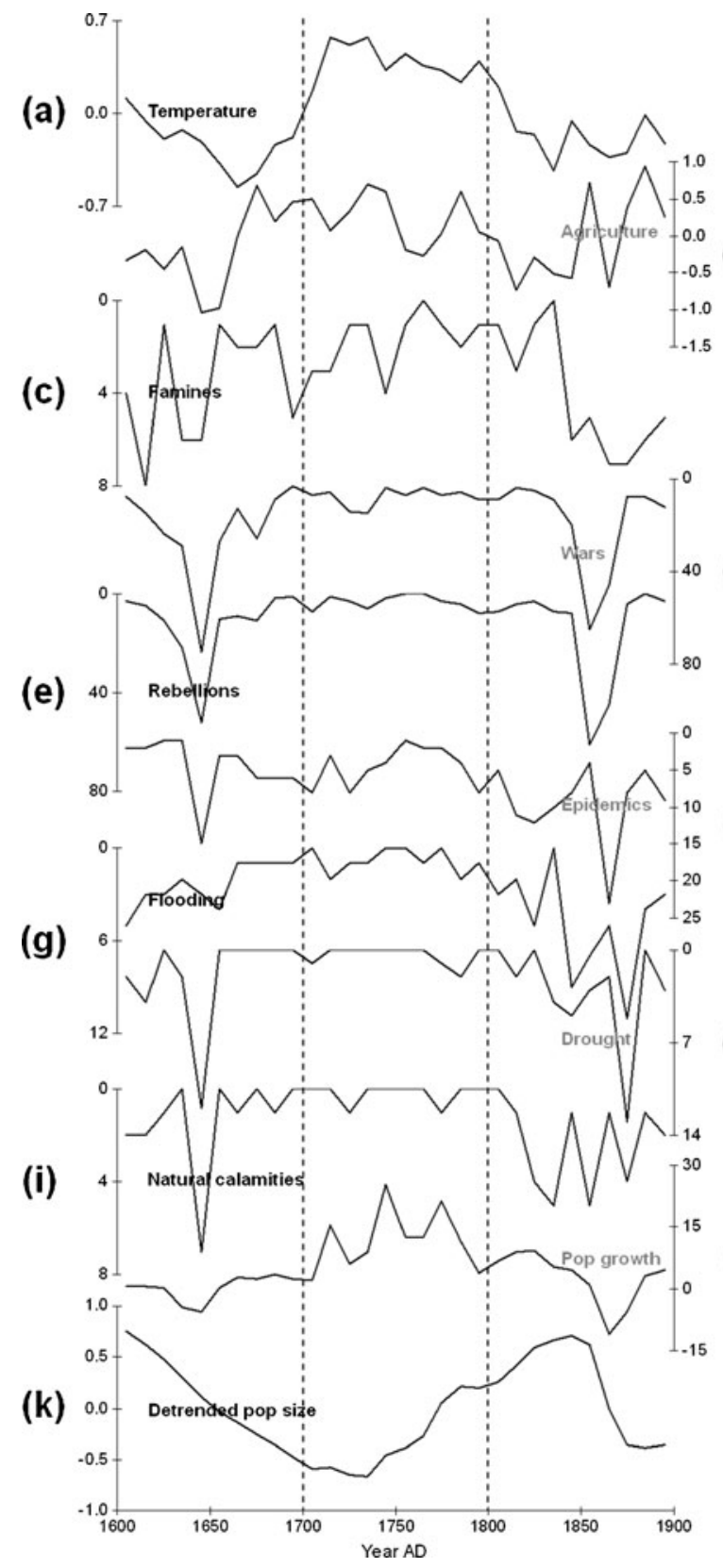

\subsubsection{Loss of life caused by famines, epidemics, and various natural disasters}

This dataset (Fig. 2g) was derived from the summation of two parameters. The first parameter is the loss of life caused by natural disasters. This data, collected by Gao (1994), records the annual casualties of flooding, drought, hail, cold spells, tidal hazards, 
landslides and earthquake for the period 1368 to 1949. The second parameter is the loss of life brought about by epidemics. This parameter is derived from Sun's (2004) pestilence dataset.

\section{Results}

\subsection{Qualitative scrutiny of climate change, population pressure and population crises}

In the early 17 th century, China entered into a cold climatic phase (Fig. 2d). In addition, her population size also surpassed 986 million. Although any direct indictor regarding the population pressure engendered by the synthesis of population expansion and cooling is not available, the pressure can be revealed by the frequent famines and nearly $0 \%$ population growth rate during the period (Fig. 2i). In fact, not only Chinese peasants, but also the nomadic tribes, were affected by the cooling. Compelled by the shrinkage of pastoral resources, the Manchu people started to invade China in 1619.

In the 1620s-1630s, Manchu invasions, peasant rebellions and a variety of natural calamities such as flooding and drought became more frequent. In 1637-1643, a severe drought (Chongzhen Great Drought) affected 23 provinces in China. There was not any rainfall in Hebei, Henan, Shanxi, Shandong and Jiangsu for 5 years (Zhang 2005). The drought led to approximately 1.18 million deaths in total. In the $1640 \mathrm{~s}$, there were 75 wars (52 of them were rebellions) (Fig. 2h), followed by 15 occurrences of pestilence. The deaths caused by famines, epidemics and various natural disasters skyrocketed to 4.43 million (Fig. $2 \mathrm{~g}$ ). Furthermore, the Ming dynasty also collapsed in this decade (1644).

Consequent upon a number of natural calamities and human catastrophes in the late Ming, population growth rate turned negative in the 1630s-1640s (Fig. 2i). Population size dropped from a peak of 99.9 million in 1626 to a trough of 88.5 million in 1646, which amounts to an $11.4 \%$ reduction in 21 years (Zhao and Xie 1988). This reduction was largely caused by warfare, as the total loss of life brought about by famines, epidemics and various natural disasters in 1626-1646 was only 4.61 million (Fig. 2g).

The cooling lasted till the end of the 17th century (Fig. 2d). The revolt of the Three Feudatories followed in 1674. The war lasted until 1681, and the agricultural base of China was further damaged during that period (Ge et al. 2004).

Temperature rose gradually from the early 18 th century and China entered into a warm phase (Zhang et al. 2005; Zhang et al. 2006; Zhang et al. 2007b) (Fig. 2d). In those good years, agricultural yield increased (Fig. 2e) and an increase of population growth rate followed (Fig. 2i). Population size expanded. Given that in the pre-industrial era, the rate of increase of population was always faster than that of subsistence level (Fig. 2a-b), population pressure mounted. The decreasing cultivated land per capita reveals this predicament (Fig. 2c). During this time, the subsistence level was co-determined by agricultural production and the availability of cultivated land. From the beginning of the Qing dynasty up to the 1720 s, there was a significant expansion of cultivated land, and the cultivated areas reached 712 million hectare in total (Fig. 2b). In fact, the expansion was mostly attributed to the resumption of agricultural activities on previously abandoned land, which was caused by the late-Ming peasant rebellions and the Manchus conquests. In the 1720s, cultivated land per capita was about 5.98 hectares (Fig. 2c). Nevertheless, cultivated areas could only expand slowly after this date. In the face of population growth, cultivated land per capita decreased accordingly. 
Much of the abovementioned increasingly adverse human/land ratio was offset by higher yields per acre, accomplished through more intensive cultivation (Perkins 1969), and by the introduction and diffusion of New World famine crops such as maize and sweet potatoes (Ho $1955,1959)$. These food plants have high yield and can be grown on land of poor quality that is not suitable for traditional crops. As the climate was favorable up until the mid-Qing, agricultural production could be maintained at a good level. In the 18th century, averaged autumn and summer harvest indexes were 8.00 and 7.58 respectively (Fig. 2e). The figures represent good and above average harvests (Gong et al. 1996). It should be noted that even though human effort seemed to be successful in boosting land productivity, the fluctuation of agricultural production (Fig. 2e) and grain storage (a proxy for social buffers) (Fig. 2f) basically followed temperature change before the Taiping Rebellion (1851).

Temperature started to decrease at the end of the 18th century, (Fig. 2d), and agricultural yield decreased accordingly (Fig. 2e), which imposed additional ecological stress on human societies on top of the existing population pressure. This period of cooling also saw frequent disasters, such as flooding and drought, that placed further ecological stress on agricultural production and then on human societies. ${ }^{4}$ Many political and social commentaries written by officials and scholars in the 19th century also indicate that the Qing dynasty started to decline in 1775-1780 (Jones and Kuhn 1978). In the late 18th century, social uprisings appeared in some remote areas. The most famous movements were the White Lotus Sect Rebellion, the uprisings of farmers led by Wang Lun and the Triad Sect (Three Harmonies Society) (Ge et al. 2004). The concurrence of dynastic decline and temperature decrease is worth considering. In the $1780 \mathrm{~s}$, the population growth rate slowed down but remained positive (Fig. 2i). As a result, total population continued to increase. A considerable cooling took place in the 1800s and China entered into a cold phase (Zhang et al. 2005; Zhang et al. 2006; Zhang et al. 2007b) (Fig. 2d). At the same time, as natural calamities became more frequent, the total grain storage in 'ever-normal granaries' dropped from 39.65 to 30.33 million shi from the 1790 s to the 1800 s, a reduction of about $24 \%$ in one decade (Fig. 2 f).

Population grew from a condition of considerable depopulation at the outset of the dynasty to unprecedented high population densities by 1800 , a phenomenon that radically altered relative supplies of land and agrarian labor and encouraged pioneering settlement of both external and internal frontiers (Rowe 2002). Sichuan, whose fertile basin had absorbed tremendous influxes of migrants during the eighteenth century, was already crowded; and even its eastern border mountains were filling up with refugees from poor harvests in other provinces. The river valleys of Guangxi, site of migration by 'guest people' (Hakka) from eastern Guangdong during the 18th century, saw intense competition for land. In mountainous western Hunan, influxes of migrants set off violent conflicts with the aboriginal Miao people by 1795. Probably the most desperate crowding existed in the lower Yangtze provinces (Jones and Kuhn 1978). The immense population growth was followed by the opening-up of mountains and hills in the inland Yangtze area, soil erosion and increasingly frequent floods in the Yangtze region in general and in the Han River drainage in particular (Ho 1959).

Around 1810, the autumn and summer harvest indexes for Northern China, the JiangHuai region, and Southern China dropped to a lower level and continued to move downward (Gong et al. 1996). In the $1810 \mathrm{~s}$, deaths caused by flooding, drought, famines and epidemics abruptly skyrocketed to 11.11 million (Fig. $2 \mathrm{~g}$ ). The casualties were mainly attributed to the

\footnotetext{
${ }^{4}$ Wang and Huang's (1999) study on the relationship between natural disasters and crop prices in the Yangtze Delta in the Qing dynasty also shows that natural disasters were one of the determining factors of agricultural production.
} 
flood-caused famines in Hebei in 1810 and 1811, which killed 11 million people in total (Gao 1997). Nevertheless, the role of those checks in downsizing population was only minor in a sense. ${ }^{5}$ Preventive checks such as conscious contraception or even infanticide might be a prevalent response to declining food supply for some populations (Lee et al. 2002; Lee et al. 1994; Lee and Wang 1999). However, their effectiveness, at most, was to slow down the population growth rate and keep the population size at a certain level, but unable to downsize the population to an 'optimum' level. Despite the above positive checks and preventive checks, the population growth rate remained positive (Fig. 2i) and population size increased. In 1829, the cultivated land per capita dropped below two hectare (Fig. 2c). Subject to the very low level of urbanization during this time, ${ }^{6}$ peasants did not have any alternative but to rely on a tiny piece of land for survival, and ecological pressure accumulated further in the face of an unfavorable climate. Social buffers, including a variety of programs to encourage agricultural production, a dynamic system of price-regulating 'evernormal granaries' and quasi-governmental 'community granaries' making seed loans to farmers and a sophisticated range of techniques, might alleviate short-term regionalized dearth (Rowe 2002). However, if agricultural production continued to decline for some years, social buffers would eventually become depleted.

In the $1840 \mathrm{~s}$, a series of famines and warfare broke out. Flooding, drought and famine were rampant. In 1849, the great flooding in Hebei, Zhejiang and Hubei provinces alone killed 15 million people (Gao 1997). In 1851, the cultivated land per capita dropped to an all time low of 1.81 hectare (Fig. 2c) and agricultural production was still heading downward (Fig. 2e). What's more, the Taiping Rebellion, the biggest civilian war in human history, broke out this year. ${ }^{7}$ In 1855 , the Nian Rebellion also broke out. Throughout the 1850 s, there were 65 wars in total (Fig. 2h), and 61 of them were rebellions. Then, in 1857, there was large scale flooding in Hubei and Shandong, which caused another eight million deaths (Gao 1997). The Taiping and Nian Rebellions ended in 1864 and 1868 respectively, and it is estimated that nearly 100 million people died during the rebellion period. However, this is not the end of the story. The 1860s was also a decade of frequent pestilence, with 23 instances breaking out. And the 3-yr drought famine in 1876-1878 led to 13 million deaths in Shanxi, Henan, Hebei and Shandong (Chen and Gao 1984).

As a result of the above human catastrophes and natural disasters, in the $1860 \mathrm{~s}$ and $1870 \mathrm{~s}$, the population growth rate was negative (Fig. 2i). This was the first time that the population growth rate turned negative since the beginning of the Qing dynasty. The population of China dropped from a peak of 440 million in 1852 to a trough of 358 million in 1870, which is about an $18.6 \%$ reduction in 19 years (Zhao and Xie 1988). At the same time, the cultivated land per capita bounced back to above 2.23 hectare (Fig. 2c). The population reduction was primarily attributed to warfare as the total number of casualties brought by

\footnotetext{
${ }^{5}$ In spite of various population checks (flooding, drought, famines and epidemics) after the 1800 s, the population growth rate remained positive, which implies that 'natural births' outnumbered the casualties brought by those population checks. In this instance, those population checks were effective in slowing down population growth, but ineffective in downsizing population.

${ }^{6}$ In 1820 , the total area of urban land use was $1,987.44 \mathrm{~km}^{2}$ in 18 provinces (including Zhili, Jiangsu, Anhui, Shanxi, Shandong, Henan, Sha'anxi, Gansu, Zhejiang, Jiangxi, Hubei, Hunan, Sichuan, Fujian, Guangdong, Guangxi, Yunnan and Guizhou). The figure is merely $0.05 \%$ of the total land area in the region (He et al. 2002).

${ }^{7}$ Taiping Rebellion started in Guangxi, which was sparked by a colossal flooding there. Besides, the spread of the rebellion from Guangxi to large parts of Southern China was closely related to serious natural disasters in other provinces and nationwide famine several years before the rebellion. Those people who joined the rebellion were mostly starved peasants (Jiang 1993).
} 
famines, epidemics and various natural disasters amounted to only 9.2 million in 1852-1870 (Fig. 2g).

\subsection{Statistical comparison of population checks in cold and warm phases}

In Fig. 3, we can see that during the cooling period of 1600-1699 (Fig. 3a), agricultural yield level as reflected by the agricultural production index was low (Fig. 3b), and the number of population checks such as famines, wars, rebellions, epidemics, flooding, drought and natural calamities was high (Fig. 3c-i). This led to a downswing in the population growth rate (Fig. 3j), and population size dropped from the peak of 99.87 million in 1626 to the trough of 88.49 million in 1646 (Fig. 3k). During the warming period of 1700-1799, agricultural yield was good, followed by low frequencies of the various population checks. This paved the way for a high population growth rate and population expansion. However, to the climate entered a cold period from 1800 to 1899 , and the peaks of various population checks resumed, which resulted in another downswing of the population growth rate. Population size dropped from a peak of 439.6 million in 1852 to a low of 357.7 million in 1870 .

Table 1 shows the average frequencies of the various population checks in both cold and warm phases. In line with the posited pathways (Fig. 1), there were more wars, rebellions, famines, epidemics, flooding, drought and natural calamities during a cold phase. Although those checks have been measured in different units, they can be compared by calculating the ratios of the annual mean of population checks between cold and warm phases (cold phase mean divided by warm phase mean). A ratio $>1$ means that the population check is more prevalent in a cold climate. With the exception of the one for epidemics, all of the ratios were $>2$. This phenomenon is particularly apparent for flooding, drought and natural calamities, as their frequencies in a cold phase were four times higher than in a warm phase.

The association between climate and the frequency of population checks has also been tested by the One-Way ANOVA (Table 1). Values of -1 and +1 were assigned to cold and warm phases, respectively (see Section 3.1 for the delineation of cold and warm phases). Then, the climatic phase was chosen as the independent ANOVA factor, while the frequency of each type of population check was entered as a dependent ANOVA factor. Statistical results showed that cold climate was significantly associated with more wars $\left(F_{1,298}=20.703, p<0.001\right)$, rebellions

Table 1 Summary of the One-Way ANOVA results of the various population checks of China, 1600-1899

\begin{tabular}{lcccccccc}
\hline & Mean & Cold period & Warm period & Cold/warm ratio & $F$ & $d f^{\mathrm{a}}$ & $d f^{\mathrm{b}}$ & $p$ \\
\hline Wars & 1.667 & 2.105 & 0.790 & 2.665 & 20.703 & 1 & 298 & $0.000^{* * *}$ \\
Rebellions & 0.890 & 1.117 & 0.330 & 3.385 & 14.447 & 1 & 298 & $0.000^{* * *}$ \\
Famines & 0.313 & 0.385 & 0.170 & 2.265 & 14.941 & 1 & 298 & $0.000^{* * *}$ \\
Epidemics & 0.623 & 0.705 & 0.460 & 1.533 & 3.631 & 1 & 298 & 0.058 \\
Flooding & 0.270 & 0.365 & 0.080 & 4.563 & 14.981 & 1 & 298 & $0.000^{* * *}$ \\
Drought & 0.187 & 0.260 & 0.040 & 6.500 & 6.151 & 1 & 298 & $0.014^{*}$ \\
Natural calamities & 0.133 & 0.190 & 0.020 & 9.500 & 11.315 & 1 & 298 & $0.000^{* * *}$ \\
\hline
\end{tabular}

\footnotetext{
${ }^{\text {a }}$ Degree of freedom (between groups).

${ }^{\mathrm{b}}$ Degree of freedom (within groups).

* Significant at the 0.05 level $(p<0.05)$.

**Significant at the 0.01 level $(p<0.01)$.

$* * *$ Significant at the 0.001 level $(p<0.001)$.
} 
$\left(F_{1,298}=14.447, p<0.001\right)$, famines $\left(F_{1,298}=14.941, p<0.001\right)$, flooding $\left(F_{1,298}=14.981, p<\right.$ $0.001)$, drought $\left(F_{1,298}=6.151, p<0.05\right)$ and natural calamities $\left(F_{1,298}=11.315, p<0.001\right)$. Although the One-way ANOVA result for epidemics was not significant $\left(F_{1,298}=3.631, p=\right.$ 0.058 ), it was just marginally insignificant at the 0.05 level; furthermore, the number of epidemics in a cold period was 1.533 times higher than that in a warm period.

\subsection{Time-series analysis of climate change, population pressure and population crises}

Given that population checks are more frequent in a cold climate (cf. Section 4.2), we postulate climate change to be an important factor in driving historic Chinese population cycles. Now we verify the various pathways in Fig. 1 by time-series analysis so as to assess the synergistic impact of population growth and climate change on population growth dynamics. The data employed in this section were shown in Fig. 3. However, some limitations should be stated in advance.

First, population pressure is determined by both agricultural production and population size. That pressure is important in driving historical Chinese population cycles. Unfortunately, no agricultural production record exists that covers the entire 1600-1899 period. Therefore, variations in agricultural production are now measured by the agricultural production index (cf. Section 3.3.1).

Second, in Fig. 1, there is a variable 'mass migration.' However, in the 1750s, Emperor Qianlong successfully conquered Tianshan ${ }^{8}$ and put many nomadic tribes under the Qing rule. Hence, the political boundary of China was extended to the west and nomadic migration disappeared in consequence. Since the variable is irrelevant in examining Chinese population cycles in the later half of the study period, it has been excluded from the following statistical analysis.

Prior to statistical analysis, all of the time series data were smoothed by the Butterworth 40 -yr low pass filter to remove the noise from the data. In this instance, the 40 -yr cycle of the variables could be elicited. ${ }^{9}$ The notion of long-term fluctuations necessarily implies some underlying trend line around which the variable under consideration appears to fluctuate. The length and amplitude of the fluctuation curve were determined by the trend line. The slope of the trend line itself may vary, depending on the nature of the variable under consideration. In order to compare between different variables and assess the 'real influence' of one variable on another over time, it is essential to remove the long-term trend (Galloway 1986, 1988). Therefore, all of the smoothed time series were linearly detrended.

Serial correlation of the time-series data prevents the application of standard tests for statistical significance. This is because assuming all data points to be independent would produce unrealistically high significance levels. In the following statistical analyses, degrees of freedom of the correlated coefficients were corrected for autocorrelation of the time-series by using the Cochrane-Orcutt estimation method. ${ }^{10}$ The minimum level of significance was chosen to be 0.05 .

\footnotetext{
${ }^{8}$ Tianshan lies to the north and west of the Taklamakan Desert in the border region of Kazakhstan, Kyrgyzstan, and the Xinjiang Uyghur Autonomous Region of western China.

9 The 40-yr cycle was elicited for the reason that paleo-temperature is usually examined in terms of its 40- or 50 -yr cycle. Therefore, all of the data series were smoothed by the Butterworth 40-yr low pass filter so that they could be compared among themselves.

${ }^{10}$ Cochrane-Orcutt iterative procedure is a differencing technique used to correct for serial correlation. A correction for autoregressive disturbances is applied using the Cochrane-Orcutt iterative procedure, where the error process is defined as $e_{t}=s_{1} e_{t-1}+u_{t}$, where $t$ is time, $e$ is the error term, $u$ is an independently distributed random variable, and $s$ is a coefficient. In a series with a moderate to large number of observations this correction should have little effect on the value of the regression coefficients, but it should provide a better estimate of their significance.
} 


\subsubsection{Temperature change and land carrying capacity}

The first part of the pathways (Fig. 1) is the direct association between climate change and agricultural production. Cooling adversely affects agricultural production, which subsequently inflicts pressure on human societies. The correlation between temperature and agricultural production index was 0.469 and significant at the 0.001 level. Due to the low level of agricultural production technology and a heavy dependence on agriculture in preindustrial societies, such a strong correlation basically reflects the vulnerability of historical Chinese societies to climate fluctuations.

\subsubsection{Temperature change, population pressure and population checks}

The relative sensitivity of different population checks to fluctuations in population pressure can be estimated by using regression analysis. In accordance with the posited pathways (Fig. 1), wars, rebellions, famines and epidemics, which are identified as 'positive checks' by Malthus, are co-determined by population pressure and natural disaster events. Given that population pressure is contingent upon population size and agricultural production, while natural disaster events include flooding, drought and natural calamities, ${ }^{11}$ all those factors are chosen to be the independent variables of these positive checks. In parallel, natural disaster events (flooding, drought and natural calamities) are, on one hand, related to population pressure. On the other hand, they are also shown to be directly associated with climate change. Therefore, population size, agricultural production and temperature were chosen to be the independent variables of the natural disaster events.

Regression results are presented in Tables 2 and 3. The coefficients of determination $\left(R^{2}\right)$ of all regression models were statistically significant. It is conceived that a larger population size will lead to a higher frequency of population checks. However, in Table 2, population size was not associated with any positive checks, while agricultural production index was negatively associated with wars $(p<0.001)$, rebellions $(p<0.001)$ and epidemics $(p<0.001)$, which means that population pressure caused by climate-induced agricultural shrinkage was imperative in causing positive checks. The insignificant association between population size and positive checks can be attributable to the dynamic relationship between the two variables. When population check frequencies reach a certain level, they will lead to an immediate and rapid decline of population size (and also population pressure). Hence, there will be some periods of high frequency of population checks while population pressure is dropping. This leads to a 'paradoxical situation' which disrupts the positive linkage between population size and population checks (Korotayev et al. 2006). In the same time period, the influence of natural calamities upon positive checks was diverse, which was only positively associated with epidemics $(p<0.001)$. Nevertheless, flooding was positively associated with wars $(p<0.001)$, rebellions $(p<0.001)$, famines $(p<0.001)$ and epidemics $(p<0.001)$, while drought was positively associated with wars $(p<0.001)$, rebellions $(p<0.001)$ and famines $(p<0.001)$. In general, natural disaster events were also important in triggering positive checks.

In Table 3, population size was positively associated with flooding $(p<0.05)$ and natural calamities $(p<0.05)$, while agricultural production index was only negatively associated with natural calamities $(p<0.001)$. Population pressure bred by population expansion was revealed to be important in causing natural disaster events. When compared with the positive checks (Table 2), the natural disaster events were shown to be more tightly linked to human

${ }^{11}$ Natural calamities include those climatic disasters such as typhoons, cold spells, flooding, drought, famines and epidemics with $>10,000$ casualties (Chen and Gao 1984). 


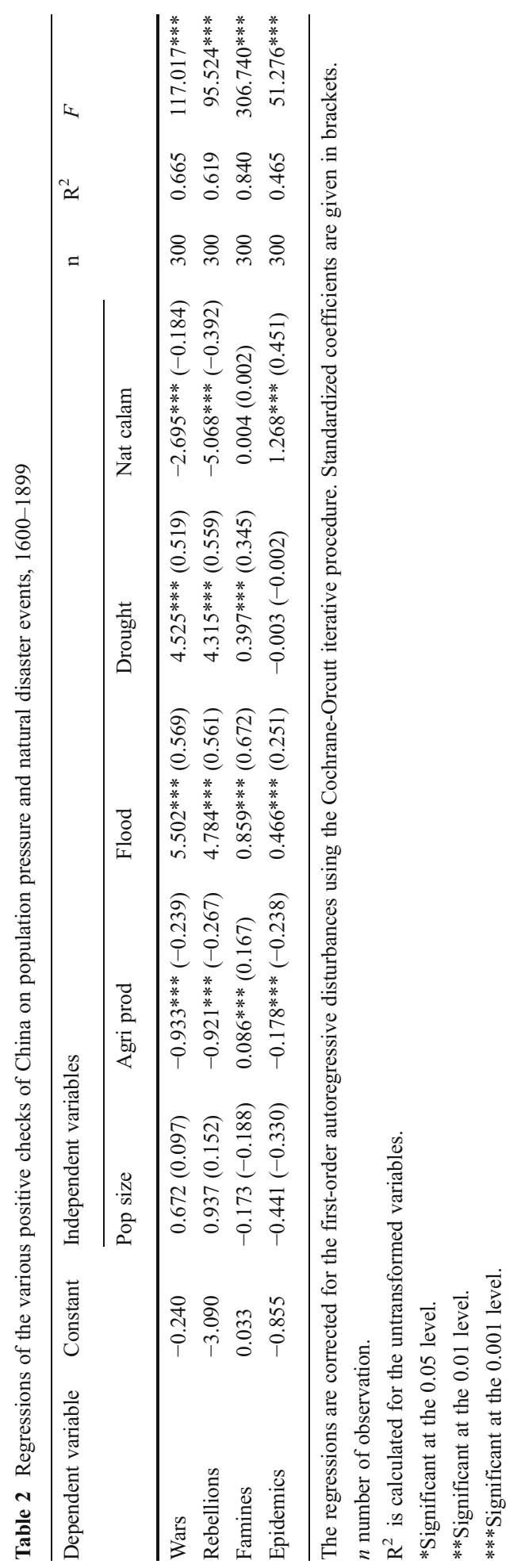


Table 3 Regressions of the natural disaster events of China on population pressure and temperature, 1600-1899

\begin{tabular}{|c|c|c|c|c|c|c|c|}
\hline \multirow{2}{*}{$\begin{array}{l}\text { Dependent } \\
\text { variable }\end{array}$} & \multirow[t]{2}{*}{ Constant } & \multicolumn{3}{|c|}{ Independent variables } & \multirow[t]{2}{*}{$\mathrm{n}$} & \multirow[t]{2}{*}{$\mathrm{R}^{2}$} & \multirow[t]{2}{*}{$F$} \\
\hline & & Pop size & Agri prod & Temp & & & \\
\hline Flooding & 0.076 & $0.088 *(0.123)$ & $0.008(0.020)$ & $-0.114 *(-0.124)$ & 300 & 0.386 & $\begin{array}{c}61.935 \\
* * *\end{array}$ \\
\hline Drought & 0.556 & $-0.004(-0.005)$ & $-0.119(-0.265)$ & $0.153 * *(0.151)$ & 300 & 0.284 & $\begin{array}{c}39.143 \\
* * *\end{array}$ \\
\hline $\begin{array}{l}\text { Natural } \\
\text { calamities }\end{array}$ & 0.045 & $0.059 *(0.126)$ & $-0.079 * * *(-0.295)$ & $-0.192 * * *(0.321)$ & 300 & 0.622 & $\begin{array}{c}160.635 \\
* * *\end{array}$ \\
\hline
\end{tabular}

The regressions are corrected for the first-order autoregressive disturbances using the Cochrane-Orcutt iterative procedure. Standardized coefficients are given in brackets.

$n$ number of observation.

$\mathrm{R}$ is calculated for the untransformed variables.

*Significant at the 0.05 level.

**Significant at the 0.01 level.

***Significant at the 0.001 level.

activity. Besides, temperature was negatively correlated with flooding $(p<0.05)$ and natural calamities $(p<0.001)$, which means that cooling led to more flooding and natural calamities. These findings basically support the posited pathways. However, the positive association was also found between temperature and drought $(p<0.001)$. It was contradictory to the hypothesized relationship. Regarding the above contradiction, there are some points to be noted. Although literature (Ren 1987; Zheng et al. 2001) and the statistical results in this study (see Table 1) suggest that more drought occurs in a cold climate, this relationship could not be replicated in this regression analysis. One possible explanation is that the temperature-drought relationship is complex, which varies with the timescale examined. The relationship may only be valid at a longer timescale (i.e., cold versus warm phases), but not valid at the annual to decadal scales. Since the regression analysis in this section focused on the 40-yr cycles of the variables, it could not capture the temperature-drought relationship. This explanation is a tentative one, which needs to be examined in detail with much more evidence.

\subsubsection{Coincidence among population checks}

At first glance, as Fig. 3 shows, the various population checks were positively correlated because their ups and downs were basically synchronistic. Cross-correlation analysis has been conducted to examine the general coincidence among the population checks. Results showed that, except for the flooding-drought association, all of the population checks were significantly positively correlated (Table 4). This suggests possible 'symbiotic' linkages among the population checks. Moreover, some of the correlations merit greater emphasis. For instance, wars and rebellions were strongly correlated $(r=0.956, p<0.001)$ for the reason that the total number of wars in the selected period was mainly attributed to rebellions, especially after the $1750 \mathrm{~s}$. Wars were temporally coincident with flooding $(r=0.567, p<$ $0.001)$ and drought $(r=0.481, p<0.001)$. It is the same for rebellions; their correlations with flooding and drought were 0.539 and 0.404 respectively. Both of the correlations were significant at the 0.001 level. In addition, epidemics were also coincident with wars $(r=$ 
Table 4 Cross correlations among the various population checks of China, 1600-1899

\begin{tabular}{lcccccc}
\hline & Rebellions & Famines & Epidemics & Flooding & Drought & Natural calamities \\
\hline Wars & $0.956^{* * *}$ & $0.197^{* * *}$ & $0.539^{* * *}$ & $0.567^{* * *}$ & $0.481^{* * *}$ & $0.287^{* * *}$ \\
Rebellions & & $0.221^{* * *}$ & $0.502^{* * *}$ & $0.539^{* * *}$ & $0.404^{* * *}$ & $0.121^{*}$ \\
Famines & & & $0.134^{*}$ & $0.643^{* * *}$ & $0.313^{* * *}$ & $0.176^{* *}$ \\
Epidemics & & & & $0.268^{* * *}$ & $0.306^{* * *}$ & $0.501^{* * *}$ \\
Flooding & & & & & 0.001 & $0.125^{*}$ \\
Drought & & & & & $0.557^{* * *}$ \\
\hline
\end{tabular}

The correlation coefficients are corrected for the first-order autoregressive disturbances using the CochraneOrcutt iterative procedure.

Number of observation $=300$.

*Significant at the 0.05 level.

** Significant at the 0.01 level.

***Significant at the 0.001 level.

$0.539, p<0.001)$ and rebellions $(r=0.502, p<0.001)$. These cross-correlations suggest the following interrelationship: flooding and drought might be the triggers of wars and rebellions ${ }^{12}$ (Ye et al. 2004), resulting in epidemics at the end ${ }^{13}$ (Gong 2003).

Although the correlation coefficients between famines and some population checks such as wars $(r=0.197, p<0.001)$, rebellions $(r=0.221, p<0.001)$ and epidemics $(r=0.134, p<$ $0.05)$ were significant, they were not very strong. This can be explained by their different patterns of occurrence. As shown in Fig. 3, famines happened when agricultural production (as revealed by tree-ring widths) shrank, while wars, rebellions and epidemics only erupted in the midst of a cold period. On the other hand, famines were more coincident with natural disasters such as flooding $(r=0.643, p<0.001)$ and drought $(r=0.313, p<0.001)$. While it is true that both flooding and drought disasters were more abundant in a cold climate, their 40$\mathrm{yr}$ cycles were shown to be totally uncorrelated $(r=0.001, p>0.05)$. Lastly, natural calamities had good coincidence with epidemics $(r=0.501, p<0.001)$ and drought $(r=0.557, p<0.001)$, which suggests that the total number of natural calamities might be primarily attributed to epidemics and drought.

\subsubsection{Population checks and population growth rate}

It is also important to examine which population checks are more pertinent to the oscillation of the population growth rate in historical China. This can be done by correlating population growth rate with the various population checks. Results show that, except for natural calamities, all of the population checks were significantly negatively correlated with population growth rate in historical China (Table 5). This suggests that those population checks significantly determined the pathway of population growth. In brief, the more the population

\footnotetext{
${ }^{12}$ At the regional scale, Ye et al. (2004) also find a correlation between wars and natural disasters such as flooding and drought (especially the latter) in Shandong during the mid and late Qing dynasty (1800-1911). Of course, the influence of other social factors such as population pressure, land tax and government policies in provoking warfare should not be overlooked. History also tells us that the wave of rebellions in the lateMing dynasty was triggered by a massive drought, while the Taiping Rebellion in the Qing dynasty was sparked by colossal flooding.

${ }^{13}$ In the years of the Qing dynasty to which the study period belongs, the role of increasing population pressure in epidemic outbreaks should also be emphasized (Gong 2003).
} 
Table 5 Correlations between the various population checks and annual population growth rate of China, 1600-1899

Annual population growth rate

\begin{tabular}{lc}
\hline Wars & $-0.703 * * *$ \\
Rebellions & $-0.764 * * *$ \\
Famines & $-0.322^{* * *}$ \\
Epidemics & $-0.464 * * *$ \\
Floods & $-0.535^{* * *}$ \\
Droughts & $-0.401^{* * *}$ \\
Natural calamities & -0.063 \\
\hline
\end{tabular}

The correlation coefficients are corrected for the first-order autoregressive disturbances using the CochraneOrcutt iterative procedure.

Number of observation $=300$.

* Significant at the 0.05 level.

**Significant at the 0.01 level.

***Significant at the 0.001 level.

checks, the lower the population growth rate. The population growth rate was particularly correlated with positive checks, particularly wars $(r=-0.703, p<0.001)$ and rebellions $(r=$ $-0.764, p<0.001)$. These results match the periods of Chinese history in which her population oscillations were primarily caused by internecine warfare (Chu and Lee 1994), and also echo with the paradoxical situation (i.e., the insignificant association between population size and positive checks, cf. Section 4.3.2). The insignificant correlation between natural calamites and population growth rate $(r=-0.063, p>0.05)$ might be caused by the relatively low frequency of extreme events, and hence their total effect on population growth rate was small.

Three points can be summarized from the above time-series analysis. First, it has been mentioned in Section 4.2 that population checks were more frequent in a cold climate. Here the statistical results support the idea that most of the population checks were not only negatively correlated with temperature change, but also positively correlated among themselves. The later finding may indicate a symbiotic relationship among the population checks. Second, the fluctuation of population checks was ultimately reflected in the oscillation of population growth rate, while warfare played the most important part in upsetting population growth rate. Finally, the interrelation between population growth, climate change and population crises basically followed our posited pathways (Fig. 1), in which the alternation of population growth and decline was significantly determined by the synthesis of population growth and climate change in recent Chinese history.

In China, cold temperature is often associated with monsoon failure. In cold phases, cold and arid winter monsoon is more influential in China; in mild phases, China is dominated by warm and humid summer monsoon (An 2000). Consequently, climate in china is alternated between cold-dry and warm-wet. There are also individual regional case studies which emphasize the agricultural impact of drought and its associated demographic consequences (Fang et al. 2007). Precipitation may overwhelm temperature in affecting agricultural productivity in regional setting. However, the regional variability of precipitation is much more varying and complex than that of temperature. Up till now, there is not any published high-resolution China-wide paleo-precipitation record. Hence, the quantitative scrutiny between precipitation and population cycle for the whole of China cannot be performed at the moment. 


\section{Discussion}

Other studies have considered the impact of population growth or climate change, individually, upon population. When explaining historical Chinese population cycles, they seldom take the two factors into account together (cf. Introduction). In the present study, we focus on the interrelation between population growth, climate change and population crises. We demonstrate how population growth and climate change worked synergistically to drive the alternation of population growth and population decline according to the posited pathways (Fig. 1) in recent Chinese history. Our findings suggest the following implications:

\subsection{Challenge to Malthusian and post-Malthusian views}

In the discussions of population pressure upon food supplies, Malthus (1798) assumes land carrying capacity to be essentially constant or possibly monotonically increasing. Positive checks (famine, epidemics and wars) and their associated population collapses occur when population growth overshoots the level of livelihood resources. In the classic Malthusian view, population is the active factor, while land carrying capacity is understood as relatively fixed. In this view, the root of historical population crises can simply be attributed to massive shortages for the whole society brought on by excessive population growth. Malthus (1798) understands population cycles as autonomous and self-generating processes. His approach remains heuristically useful in many ways. Nevertheless, when the classic Malthusian view is mapped onto empirically observed patterns in historical societies, the immediate shortcoming is clear: population growth alone cannot predict the exact time when there will be population contractions and the duration of each contraction. Those explanations at most can only account for the recurrence of cycles, while the differences/irregularities between cycles (e.g., timing, duration, magnitude, velocity and momentum) cannot be answered satisfactorily, at least in the case of China.

Post-Malthusian scholars have developed more sophisticated models of the recurrent longterm oscillations of population size through early modern history. They emphasize that population growth causes population crises indirectly, by affecting social institutions (economic, political and social structures), which in turn affect socio-political stability. In the context of relatively inflexible economic and social structures, population increase in excess of the productivity gains of the land produces the distributional effects of relative shifts in population and resources (prices and the welfare of different sectors of society) with which agrarianbureaucratic states cannot successfully cope. Established social fabrics are stressed in several ways at once. The result is a protracted period of political disorder, social conflict and economic disruption, followed by more frequent mortality crises and demographic contractions (Goldstone 1991; Turchin 2003; Turchin and Nefedov 2009). Post-Malthusian scholars attribute the differences/irregularities between cycles to various exogenous factors that are not an explicit part of the models. Climate change is merely one of them.

The fundamental hypothesis of this paper is that population is limited by subsistence, and population checks will come into operation when population exceeds subsistence level. This notion has a Malthusian flavor. However, this study has emphasized that, given the technological limitations of agricultural production during the time under study, long-term climatic changes would have a significant impact on food supplies, and that the constant or possibly monotonic increase in land carrying capacity (assumed by Malthus and many other scholars) is not true, at least in the pre-industrial era. The upward trend of land carrying capacity is, in fact, characterized by shorter-term recurring oscillations (ascending wave pattern) in accordance with the alternation of cold and warm climate. Pre-industrial populations always grow 
to the land carrying capacity and subsist at the minimum consumption level. Population pressure will aggregate, and the population will proceed to the state of 'hungry homeostasis' over time (Fagan 2000; Li 1998; Nefedov 2003; Wood 1998; Wrigley 1973). Such hungry homeostasis interacts with the climate-induced decline of land carrying capacity to produce a demographic (or even socio-political) collapse via the increase of various mortality crises, including war, famine, epidemics and natural calamities. This mechanism determines the socio-economic and demographic cycles in pre-industrial China. Here we challenge both the classic Malthusian and post-Malthusian views that deteriorating climate change appears to be fundamental, not incidental, in causing human misery and the resultant population crises in Chinese history. Furthermore, the mechanism is not population growth alone, but population growth and climate change working synergistically to drive secular population cycles in historical agrarian China.

\subsection{Human fault versus system default}

Many historians attribute the clusters of natural calamities and human catastrophes in Chinese history to defects in the social, economic and political institutions that lay deep in the pattern of rule. The declining dynastic government was often characterized by gradual loss of normative controls over the nation and inability to supply her people with sufficient livelihood resources. To the nomadic tribes outside China, this circumstance provided them with good chances to invade the weakening empire for land and resources. At the same time, at all levels of society within China, people took to arming themselves in order to acquire the minimum level of subsistence necessary for their daily life. Such a combination bred growing political defiance and social breakdown and a series of natural calamities and human catastrophes which were simply too much for the antiquated Chinese government, bureaucracy and economy to deal with. Ultimately, dynastic changes occurred, while population collapses are taken to be the 'by-products' of the above process (Huang 1988; Wright 1965; Zhao 1994). According to this reasoning, the root of population crises can be traced back to 'human fault.'

In this study, however, we show that in agrarian China, population growth always caught up with the elevation of subsistence level. This phenomenon is reflected by the decreasing cultivated land per capita (Fig. 2c). Population stress was autonomously bred in preindustrial societies, which could drive the cycles of population crises. Apart from 'autonomous' population pressure, long-term climate deterioration will impose additional stress on human societies. ${ }^{14}$

Famines, epidemics and various natural disasters became more rampant in a cold climate. Nevertheless, they were only effective in slowing down population growth, and were ineffective in downsizing the population for the reason that 'new births' always outnumbered the casualties caused by these population checks. Therefore, notwithstanding the prevalence of population checks, the population growth rate was still positive and hence, population size kept on increasing (cf. Section 4.1). In the short-term, social buffers might help human societies to move on in such a difficult time. In the long-term, if cooling continued, social buffers simply allowed the continual increase of population, which in turn facilitated the building of population pressure beyond a threshold. Once the social buffers

\footnotetext{
${ }^{14}$ Climatic extremes of 1- to 2-yr length may have their immediate effect on pre-industrial societies. Malthus (1798) takes them to be the exogenous shocks on population. However, in this study, it is emphasized that long-term climatic change, which he has not mentioned, is more pertinent in driving the population cycles in historical China.
} 
were depleted, the accumulated population pressure was unleashed via internecine warfare, resulting in population collapses (Lee and Zhang 2010). In fact, the above scenario, brought by population growth and climate change, is entirely beyond the managing capacity of any emperor/government within the context of historical agrarian China. Given that the recurrence of population crises is evidence of a system (Hall and Turchin 2007), and it can be explained by the posited pathways (Fig. 1), we may say that the crises are rooted in the 'system default' instead of 'human fault'.

The meanings of 'natural calamities' and 'human catastrophes' can be further examined. Natural calamities include flooding, drought and so on; human catastrophes include wars, rebellions and the like. 'Natural' and 'human' are the most widely accepted lexicons in categorizing population checks according to their origins: the former one is primarily predestined by the heavens; the latter one is more a result of human fault. However, histories reveal that both natural calamities and human catastrophes are clustered in periods of cold climate. In fact, both of them are rooted in the same factor (i.e., the synthesis of population growth and climate change), as shown in the posited pathways (Fig. 1). Hence, those lexicons may be misleading in categorizing population checks.

\section{Conclusions}

In China in the past millennium, the clustering of natural calamities and human catastrophes in times of cold climate was found not only in one or two cold phases, but in all of the cold phases (Lee and Zhang 2010). And in a cold climate, many things went wrong not only in China, but also in many parts of the world where the population system had already pushed against its Malthusian constraints (Zhang et al. 2011; Zhang et al. 2007a). The 'General Crisis of the Seventeenth Century ${ }^{15}$ is the most typical case. This is because cooling in the past millennium has been a hemispheric-wide phenomenon, which is often associated with significant changes in temperature, precipitation, and wind patterns in many parts of the world and hence, generates a devastating impact on agricultural production everywhere (Atwell 2001, 2002). The impact was ultimately translated into a series of catastrophic deterrents. We dare not generalize the climate-population relationship in recent Chinese history to other parts of the world. But, given that climatic anomalies and particularly the declines in temperatures often have had catastrophic consequences for the world's food supply, it might be well for scholars to keep climate change in mind as they consider socalled 'human history' (Hinsch 1988).

Acknowledgments The research grant generously provided by the HKU Seed Funding Programme for Basic Research for the project entitled, 'Revealing the Long-term Dynamics of Drought: The Reconstruction of Drought History in Northwestern China over the Past Millennium' (201109159014) and Research Grants

\footnotetext{
${ }^{15}$ The General Crisis is the term used by some historians to describe the period of widespread conflict and instability that occurred from the early 17 th century to the early 18 th century in Europe and in more recent historiography in the world at large. During that time, the crown of the Holy Roman Empire was unsettled by the Thirty Years' War. Civil war devastated France and forced the mother of Louis XIV to flee with her children from Paris. In London, Charles I was condemned to death by his own subjects. Philip IV, King of Spain, lost almost all his possessions in Asia and also lost Portugal. The period is also characterized by simultaneous waves of popular uprisings: the Puritan Revolution in England, flanked by the revolts of Scotland and Ireland; the insurrections in the Spanish monarchy - Catalonia and Portugal in 1640, Naples and Palermo in 1647; the Fronde in France between 1648 and 1653; the bloodless revolution of 1650, which displaced the stadtholderate in the Netherlands; the revolt of the Ukraine from 1648 to 1654; and a string of peasant risings across the continent (Parker and Smith 1978).
} 
Council of The Government of the Hong Kong Special Administrative Region of the People's Republic of China for the project entitled, 'Climate Change and War-peace Cycles in Eurasia in Recent Human History' (HKU7055/08 H) are gratefully acknowledged. Last but not least, a special thanks to Dr. Cynthia Rosenzweig and the referees for their valuable comments on the manuscript.

Open Access This article is distributed under the terms of the Creative Commons Attribution License which permits any use, distribution, and reproduction in any medium, provided the original author(s) and the source are credited.

\section{References}

An ZS (2000) The history and variability of the East Asian paleomonsoon climate. Quat Sci Rev 19:171-187 Atwell WS (2001) Volcanism and short-term climatic change in East Asian and world history, c. 1200-1699. J World Hist 12:29-98

Atwell WS (2002) Time, money, and the weather: Ming China and the 'great depression' of the mid-fifteenth century. J Asian Stud 61:83-113

Chao K (1986) Man and land in Chinese History: an economic analysis. Stanford University Press, Stanford

Chen T (1946) Population in Modern China. The University of Chicage Press, Chicago

Chen Y, Gao J (1984) Time characteristics of great climatic disasters of died people over ten thousand in Chinese history. Discovery of Nature:157-166.

Chen F, Yu Z, Yang M, Ito E, Wang S, Madsen DB, Huang X, Zhao Y, Sato T, Birks HJB, Boomer I, Chen J, An C, Wuennemann B (2008) Holocene moisture evolution in arid central Asia and its out-of-phase relationship with Asian monsoon history. Quat Sci Rev 27:351-364

Chen FH, Chen JH, Holmes J, Boomer I, Austin P, Gates JB, Wang NL, Brooks SJ, Zhang JW (2010) Moisture changes over the last millennium in arid central Asia: a review, synthesis and comparison with monsoon region. Quat Sci Rev 29:1055-1068

Chi CT (1963) Key economic areas in Chinese history as revealed in the development of public works for water-control. Paragon Book Reprint Corp, New York

Chu CYC, Lee RD (1994) Famine, revolt, and the dynastic cycle - Population dynamics in historical China. J Popul Econ 7:351-378

Editorial Committee of Chinese Military History (1985) Zhongguo Junshishi. Jiefangjun Chubanshe, Beijing

Fagan B (2000) The Little Ice Age: How Climate Made History 1300-1850. Basic Books, New York

Fan K-w (2010) Climatic change and dynastic cycles in Chinese history: a review essay. Clim Chang 101:565-573

Fang JQ, Liu G (1992) Relationship between climatic change and the nomadic southward migrations in eastern Asia during historical times. Clim Chang 22:151-169

Fang X, Ye Y, Zeng Z (2007) Extreme climate events, migration for cultivation and policies: a case study in the early Qing dynasty of China. Sci China Earth Sci 50:411-421

Galloway PR (1986) Long-term fluctuations in climate and population in the preindustrial era. Popul Dev Rev $12: 1-24$

Galloway PR (1988) Basic patterns in annual variations in fertility, nuptiality, mortality, and prices in preindustrial Europe. Popul Stud 42:275-303

Gao J (1994) Research on the parameters of natural disasters. J Catastrophology 9:65-73

Gao W (1997) Zhongguo Ziran Zaihaishi (Zonglun). Dizhen Chubanshe, Beijing

Ge QS, Dai JH, He FN, Zheng JY, Man ZM, Zhao Y (2004) Spatiotemporal dynamics of reclamation and cultivation and its driving factors in parts of China during the last three centuries. Progress in Natural Science 14:605-+.

Goldstone JA (1991) Revolution and Rebellion in the Early Modern World. University of California Press, Berkeley

Gong S (2003) Changes of the temporal-spatial distribution of epidemic disasters in 770 BC - AD 1911 China. Acta Geogr Sin 58:870-878

Gong G, Ge Q, Xu K (1996) Qihou bianhua dui nongye de yingxiang. In: Zhang P (ed) Zhongguo Lishi Qihou Bianhua. Shandong Kexue Jishu Chubanshe, Jinan

Gribbin J (1978) Climatic Change. Cambridge University Press, Cambridge

Hall TD, Turchin P (2007) Lessons from population ecology for world-systems analyses of long-distance synchrony. In: Hornborg A, Crumley CL (eds) The World System and the Earth System. Left Coast Press, Walnut Creek, pp 74-90 
He F, Ge Q, Zheng J (2002) Reckoning the areas of urban land use and their comparison in the Qing dynasty in China. Acta Geogr Sin 57:709-716

Hinsch B (1988) Climatic change and history in China. J Asian Hist 22:131-159

Ho PT (1955) The introduction of American food plants into China. Am Anthropol 57:191-201

Ho PT (1959) Studies on the Population of China. Harvard University Press, Cambridge, pp 1368-1953

Huang R (1988) China, a macro history. M.E. Sharpe, Armonk

Institute of History Chinese Academy of Social Sciences (1988) Zhongguo Lidai Ziran Zaihai ji Lidai Shengshi Nongye Zhengce Ziliao. Nongye, Beijing

Ji X (1989) Studies in Honour of Professor Chen Yin-que. Beijing Daxue Chubanshe, Beijing

Jiang T (1993) Zhongguo Jindai Renkou Shi. Hangzhou University Press, Hangzhou

Jiang L, Sun Y, Ba M (2004) On the climate affecting Chinese political, economical, historical structure evolution. J Chengdu Coll Educ 18(3-4):10

Jones SM, Kuhn PA (1978) Dynastic decline and the roots of rebellion. In: Fairbank JK (ed) The Cambridge History of China, vol 10, Late Ch'ing, 1800-1911. Part I. Cambridge University Press, Cambridge, pp $107-162$

Korotayev AV, Malkov AS, Khaltourina DA (2006) Secular cycles and millennial trends. In: Korotayev AV, Malkov AS, Khaltourina DA (eds) Introduction to social macrodynamics: secular cycles and millennial trends. Editorial URSS, Moscow, pp 95-133

Lan Y, Jiang L (2005) On the climate affecting Chinese political and economical structure. J Qinghai Natl Inst (Soc Sci) 31:44-47

Lattimore O (1988) Inner Asian Frontiers of China. Oxford University Press, Hong Kong

Lee JZ, Wang F (1999) One Quarter of Humanity: Malthusian Mythology and Chinese Realities, 1700-2000. Harvard University Press, Cambridge

Lee HF, Zhang DD (2010) Changes in climate and secular population cycles in China, $1000 \mathrm{CE}$ to 1911. Clim Res 42:235-246

Lee J, Wang F, Cameron C (1994) Infant and child-mortality among the Qing nobility: Implications for 2 types of positive check. Popul Stud 48:395-411

Lee J, Cameron C, Wang F (2002) Positive check or Chinese checks? J Asian Stud 61:591-607

Lee HF, Fok L, Zhang DD (2008) Climatic change and Chinese population growth dynamics over the last millennium. Clim Chang 88:131-156

Lee HF, Zhang DD, Fok L (2009) Temperature, aridity thresholds, and population growth dynamics in China over the last millennium. Clim Res 39:131-147

Li X (1998) Renkou dongtai pingheng de lishi fenxi. Journal of Historical Science:110-117.

Li Y (1999) Qianlun zhongyuan diqu jin wuqiannian lai qihou de shuihan bianhua guilu yu zhongguo lishi chaodai de yanti yu xingshuai. J North China Inst Water Conserv Hydroelectr Power (Soc Sci) 15:37-41

Liang F (1980) Zhongguo Lidai Hukou, Tiandi, Tianfu Tongji. Shanghai Renmin Chubanshe, Shanghai

Liu Z (1994) Zhongguo Lishi shang Qihou zhi Bianqian. Taiwan Shangwu, Taibei

Long G (1989) Neiyou waihuan yu qihou bianqian. Geographical Knowledge:24-25.

Malthus TR (1798) An Essay on the Principle of Population. printed for J. Johnson, London.

Man Z (2009) Zhongguo Lishi Shiqi Qihou Bianhua Yanjiu. Shandong Jiaoyu Chubanshe, Jinan

Nefedov SA (2003) A theory of demographic cycles and the social evolution of ancient and medieval oriental societies. Vostok-Oriens 3:5-22

Pan Y (1994) Zhongguo lishi shang nongmu chongtu de dili jieshi. Journal of Qiqihar University (Philosophy Social Science Edition):87-92.

Parker G, Smith LM (1978) Introduction. In: Parker G, Smith LM (eds) The general crisis of the seventeenth century. Routledge \& Kegan Paul, London, pp 1-25

Peng X (1965) History of Chinese currency. Shanghai People's Press, Shanghai

Perkins DH (1969) Agricultural development in China, 1368-1968. Aldine, Chicago

Reischauer EO (1965) The dynastic cycle. In: Meskill J (ed) The pattern of Chinese history: cycles, development, or stagnation? D.C. Heath \& Co., Boston, pp 31-33

Ren Z (1987) The abnormal periods of climate in China over the past 5000 years and their causes. Adv Atmos Sci 4:210-217

Rowe WT (2002) Social stability and social change. In: Peterson WJ (ed) The Cambridge History of China, vol 9, Part One: The Ch'ing Empire to 1800. Cambridge University Press, Cambridge, pp 473-562

Stenseth NC, Voje KL (2009) Easter Island: climate change might have contributed to past cultural and societal changes. Clim Res 39:111-114

Sun G (2004) Research of dispersed in time and space untal regularity of Chinese historical big pestilence. Areal Res Dev 23:123-128

Tan M, Liu TS, Hou JZ, Qin XG, Zhang HC, Li TY (2003) Cyclic rapid warming on centennial-scale revealed by a 2650-year stalagmite record of warm season temperature. Geophysical Research Letters 30:Art. No. 1617. 
Tang M, Tang C (2000) The impact of climate variation on the history evolution of China. Plateau Meteorol 19:159-165

Tang M, Tang C (2002) Climatic condition and Chinese history (II): "Good (bad) climatic condition" and "peaceful (trouble) times" in Chinese history. Plateau Meteorol 21:15-19

Turchin P (2003) Historical dynamics. Princeton University Press, Princeton

Turchin P (2005) Dynamical feedbacks between population growth and sociopolitical instability in agrarian states. Structure and Dynamics: eJournal of Anthropological and Related Sciences 1:Article 3.

Turchin P (2006) War and peace and war: the life cycles of imperial nations. Pi Press, New York

Turchin P, Nefedov SA (2009) Secular cycles. Princeton University Press, Princeton

Usher D (1989) The dynastic cycle and the stationary state. Am Econ Rev 79:1031-1044

Wang YC (1936) The rise of land tax and the fall of dynasties in Chinese history. Pac Aff 9:201-220

Wang H (1996) The relationship between the migrating south of the nomadic nationalities in north China and the climatic changes. Sci Geogr Sin 16:274-279

Wang Y, Huang Y (1999) Qingdai zhongguo qihou bianqian, ziran zaihai yu liangshi de chubu kaocha. Researches in Chinese Economic History:3-18.

Wang SW, Gong DY, Zhu JH (2001) Twentieth-century climatic warming in China in the context of the Holocene. Holocene 11:313-321

Wood JW (1998) A theory of preindustrial population dynamics - Demography, economy, and well-being in malthusian systems. Curr Anthropol 39:99-135

Wright AF (1965) Comment on early Chinese views. In: Meskill J (ed) The pattern of Chinese history: cycles, development, or stagnation? D.C. Heath \& Co., Boston, pp 3-4

Wrigley EA (1973) Population and history. Weidenfeld and Nicolson, London

Wu J (2003) Shilun zhongguo gudai renkou zengjian yu wangchao xingshuai guanxi ji qishi. J Southwest China Norm Univ (Philos Soc Sci Ed) 29:113-116

Xiao X (2005) The laws of ancient Chinese agriculture social population's variety. J Yanan Univ (Soc Sci) 27:83-86

Yang B, Braeuning A, Johnson KR, Shi Y (2002) General characteristics of temperature variation in China during the last two millennia. Geophysical Research Letters 29:Art. No. 1324.

Ye Y, Fang X, Ge Q, Zheng J (2004) Response and adaptation to climate change indicated by the relationship between revolt and drought-flood in Shandong Province during middle and late Qing dynasty. Sci Geogr Sin 24:680-686

Zhang C (1999) A study of the climate effects on the society of China during historical times. J Xinjiang Norm Univ (Nat Sci Ed) 18:49-52

Zhang D (2005) Severe drought events as revealed in the climate records of China and their temperature situations over the last 1000 years. Acta Meteorol Sin 19:485-491

Zhang W, Li P (1999) Lishi shiqi renkou yu shuizai guanxi tantao. Popul Res 23:25-31

Zhang D, Jim CY, Lin CS, He YQ, Lee F (2005) Climate change, social unrest and dynastic transition in ancient China. Chin Sci Bull 50:137-144

Zhang DD, Jim CY, Lin GCS, He YQ, Wang JJ, Lee HF (2006) Climatic change, wars and dynastic cycles in China over the last millennium. Clim Chang 76:459-477

Zhang DD, Brecke P, Lee HF, He YQ, Zhang J (2007a) Global climate change, war, and population decline in recent human history. Proc Natl Acad Sci U S A 104:19214-19219

Zhang DD, Zhang J, Lee HF, He YQ (2007b) Climate change and war frequency in Eastern China over the last millennium. Hum Ecol 35:403-414

Zhang DD, Lee HF, Wang C, Li B, Zhang J, Pei Q, Chen J (2011) Climate change and large scale human population collapses in the pre-industrial era. Global Ecol Biogeogr 20:520-531

Zhao S (1994) Geography of China: environment, resources, population, and development. John Wiley \& Sons, New York

Zhao W, Xie S (1988) Zhongguo Renkou Shi. Renmin Chubanshe, Beijing

Zheng J, Zhang P, Ge Q, Man Z (2001) Centennial changes of drought/flood spatial pattern in eastern China for the last 2000 years. Prog Nat Sci 11:280-287

Zhou Z (1997) Zhongguo fengjian shehui de renkou zhouqi xiaozhang yu huangchao zhouqi xunhuan guanxi zhi tantao. J Hangzhou Univ 27:71-78 